\title{
Discussion on technical system and practice of green highway construction
}

\author{
JunHua Cai ${ }^{1}$, FuXing Liao ${ }^{1}$, JinShun Lin $^{1}$, HouCheng Zhong ${ }^{1}$, Xiaodong Shang ${ }^{2 *}$ and Dan Wang ${ }^{2}$ \\ ${ }^{1}$ Sanming Traffic Construction Group Co., Ltd. \\ ${ }^{2}$ Research Institute of Highway Ministry of Transport, Beijing, 100086, China
}

\begin{abstract}
This paper proposes the framework of the construction and management system of the Puyan Green Highway in Sanming, the technology of environmental protection and pollution prevention, the technology of resource conservation and recycling, the technology of green environmental protection and energy conservation and carbon reduction, the service improvement and smart construction technologies On this basis, the research and practice of green highway construction demonstration technology have been carried out, laying a practical foundation for the construction of green highways in Fujian Province.
\end{abstract}

\section{Introduction}

The Eighteenth National Congress of the Communist Party of China proposed to "fully implement the overall layout of the five-in-one economic construction, political construction, cultural construction, social construction, and ecological civilization construction, and promote the coordination of all aspects of modernization construction." The independent chapter systematically put forward the overall requirements for vigorously promoting the construction of ecological civilization in the next five years, and placed ecological civilization construction in a more prominent strategic position related to the comprehensive construction of a well-off society, and included it in the overall layout of socialist modernization. The report of the 18th National Congress of the Communist Party of China pointed out that in the new era of socialist ecological civilization, we must establish the concept of ecological civilization that respects nature, conforms to nature, and protects nature.

In 2016, the Ministry of Transport issued the Opinions on the Implementation of Green Highway Construction (Jiao Gong Lu [2016] No. 93), which pointed out the direction for the development of green transportation. As an important part of green transportation, green roads are highly valued by the construction of ecological civilization, and resource conservation and environmental friendliness requirements are further enhanced. With the full implementation of green road construction as the entry point to promote the development of green transportation, the road development is further transformed. Methods, promote the sustainable and healthy development of highway construction, and create a beautiful business card for the construction of ecological civilization in the transportation industry.

On January 11, 2017, the General Office of the Ministry of Transport issued the Notice on the
Construction of Typical Demonstration Projects for Green Highway Construction, and listed the Puyan expressway (Yongtai Indus to Youxi Zhongxian Section) as the second batch of green highways. Typical demonstration project. The establishment of a green highway demonstration project is an urgent need to build a modern transportation system that is safe, convenient, efficient, green, and economical, and a requirement to implement the national strategy of a powerful transportation country.

\section{Project overview}

Putian to Yanling expressway Yongtai Indus to Youxi Zhongxian Section (Sanming City) The project route is roughly east-west. The project starts at the Wulei Gap at the junction of Sanming City and Fuzhou City (the boundary point is inside the Everest Tunnel). $23.3897 \mathrm{~km}$ long. The whole line adopts the standard two-way six-lane highway construction, and the design speed is $100 \mathrm{~km} / \mathrm{h}$. Construction started at the end of November 2016, and it is planned to open to traffic by the end of 2019. There are 5,910 meters and 17 bridges on the entire line, 1636.4 meters and 6 ramp bridges, and 6004.75 meters and 4.5 tunnels. The bridge-to-tunnel ratio is $50.94 \%$. There are 2 interchanges (Zhongxian Interchange and Huakou Hub Interchange) across the entire line; and 1 service area.

*Corresponding author's e-mail: 38905936@qq.com 


\section{$3 \quad$ Engineering features and difficulties}

\subsection{The ecological environment along the line is fragile and environmental protection requirements are strict}

3.2. Mountainous and heavily hilly areas, complex engineering, scarce resources, and highly targeted demonstration technology

\subsection{Large traffic volume, high proportion of heavy loads, large space for smooth and durable technology applications}

\subsection{Beautiful natural scenery, rich tourism resources, and high landscape display positioning}

\section{General ideas}

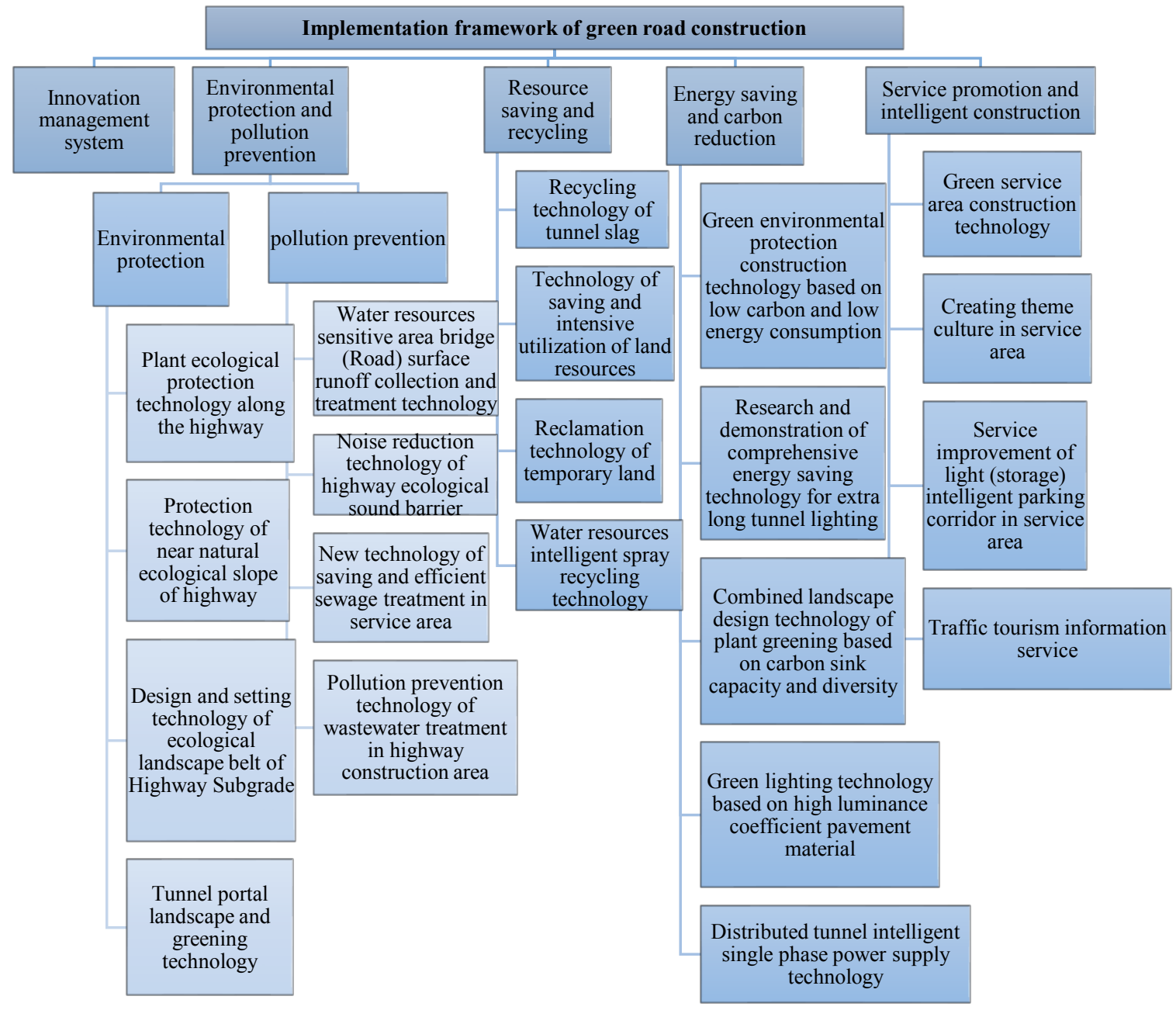

Figure 1. The implementation contents of green road construction of Puyan expressway.

\section{Main implementation schemes}

Focusing on the five aspects of innovative management system, environmental protection and pollution prevention, resource conservation and recycling, green environmental protection, energy conservation and carbon reduction, service upgrading and smart construction, the implementation content of the Puyan expressway green highway construction is shown. 
Highway, the establishment and improvement of a green highway creation management system, the innovation of the management mode, and the provision of organizational guarantee for the realization of project goals.

5.1.1. Establish a leading group for green road work. In order to create a green demonstration project, strengthen the management of soil and water conservation, and achieve the management goals of soil and water conservation, a green road work leadership group was established to take charge of the green road organization and leadership of the project.

5.1.2. Focus on refined management. Carry out research and formulation of the management mode of bundled bidding for pavement engineering and civil engineering, and bundled bidding for house construction and civil engineering, to promote the recycling of tunnel waste and coal-bearing soil, and realize less abandoned and less borrowed.

5.1.3. Strengthen standardization of quality management. The project's quality management objectives were clarified, and a series of quality management systems, standardized management manuals and atlases were formulated in accordance with the relevant systems and regulations of higher-level authorities and the actual situation of the project. Implement standardized construction management.

\subsection{Environmental protection and pollution prevention technology}

Respectively from the ecological protection of plants along the line, the protection technology of highway near natural ecological slopes, the collection and treatment of runoff from bridges (roads) in sensitive areas of highway water resources, the noise reduction technology of highway ecological sound barriers, the new technology of efficient and efficient sewage treatment in service areas, Carry out systematic research and demonstrations on wastewater treatment and anti-pollution technologies in highway construction areas, highway subgrade ecological landscape belt design and setting technology, and tunnel opening landscape and greening technologies, etc., to provide technical support for the ecological environmental protection of Puyan expressway and improve the ecological construction of Puyan expressway And natural environment restoration and protection level.

It is suggested that a fence should be added to protect the highway during the construction period to prevent the old trees from being affected by the construction. In the design phase, more old roads are used to reduce vegetation felling. In the construction phase, an "environment-friendly green line" is set up and the meter is cleared again. During the construction of the roadbed, the rope is used to release the toe line to prevent damage to the vegetation outside the line.

The near-natural ecological slope protection technology is to maximize the restoration of the natural landscape. The conventional knife-cut excavation mode is changed to simulate the shape of the original mountain body. The slope is streamlined and trimmed. The slope and pre-excavation The morphology of the mountain is basically consistent, and landscape ecological restoration and vegetation restoration are implemented.

The ecological sound barrier noise reduction technology combined with the concept of the green highway can not only achieve the noise reduction effect, but also achieve the environmental integration effect of adapting to local conditions, saving energy and reducing carbon.

\subsection{Resource saving and recycling technology}

Carry out systematic research and demonstration in terms of tunnel slag recycling technology, land resource conservation and intensive use technology, temporary land reclamation technology, and intelligent water spraying and recycling technology to improve the resource conservation and recycling in the construction of Puyan expressway usage efficiency.

There are 5 tunnels in this project, the Everest Tunnel $(855.75 \mathrm{~m})$, Shantouding Tunnel $(1881.5 \mathrm{~m})$, Yuxi No.1 Tunnel (193m), Yuxi No.2 Tunnel (2278.5m), and Xihua Tunnel $(796 \mathrm{~m})$. In the highway construction process, the comprehensive recycling technology of tunnel waste slag is used to maximize its use in tunnel lining concrete aggregates, bridge aggregates, and rough aggregates of asphalt pavement structures. In addition, fully communicate with the local towns and villages, understand the needs of township construction, and use the abandoned slag of the tunnel for local government construction projects.

The design of the newly constructed access roads should be communicated with the village and township governments as far as possible, taking into account factors such as local future development planning, forest transportation, and transportation in the new demolition and resettlement sites, in order to achieve the temporary construction of the temporary access roads to be changed to local Permanent traffic road.

\subsection{Green Environmental Protection and Energy Saving and Carbon Reduction Technology}

Firstly, in order to solve the energy-saving problems of tunnel operation, research and demonstration of comprehensive energy-saving technologies based on green lighting technology based on high-luminance pavement and distributed tunnel intelligent single-phase power supply technology were conducted. Environmental pollution, carry out research on the selection of carbon-fixing vegetation suitable for mountainous areas, integrate carbon sinks and landscape greening, and improve the exhaust pollution problems of automobile-intensive areas such as the Puyan expressway service area and toll stations.

The tunnel two-lined maintenance dust-removing spray trolley comprises a gate-shaped load-bearing frame, a walking device and a spray assembly. The spray 
component is mainly an arched spray tube and spray nozzle, a spray high-pressure machine, and a water tank; the lower end of the arched spray tube is connected to a pressurized water pump and a storage tank in order. The purpose of using the construction tool of the utility model is to provide spray curing and dust removal for the second lining of the tunnel.

\section{Experience of green highway construction work}

\subsection{Adhere to standardized construction and implement quality engineering construction}

Comprehensively and thoroughly promote the modern engineering construction management method with the content of "humanization of development concept, professionalization of project management, standardization of engineering construction, informatization of management methods, and refinement of daily management", and further explore the standard system and management mode of highway construction quality engineering to promote the improvement of the quality level of highway construction. Combined with the actual construction of Puyan expressway, focusing on improving the standardization management level of construction and ensuring quality and safety, the focus is on further improvement in management, technology, equipment, image, environmental protection, and information technology applications, which effectively promotes the standardized management of Puyan expressway construction. Take it to a new level.

\subsection{Focus on construction process control and carry out dual creation}

Strengthen organization and leadership, and strengthen the implementation of responsibilities. The project department clearly distributes work to each other. Each on-site management staff implements job responsibilities at various levels, clarifies quality standards, and effectively improves construction quality. Through observation meetings, reverse analysis meetings, etc., the construction of the Puyan expressway will be more standardized, the construction procedures will be more scientific, the construction technology will be more advanced, the construction control will be more effective, the common quality and safety problems will be curbed, and no serious quality and safety accidents will be prevented.

\subsection{Plan the layout in advance and lay a solid foundation}

At the bidding stage, great attention was paid to standardization and the creation of green highways and quality projects. Relevant requirements were also put forward in the bidding documents, addendums, and contract negotiations. Each participating construction unit carefully digested the provincial and municipal governments and Puyan Company. The related guidance documents issued by Shuanghuang, combined with the characteristics of the project, formulated the "Shuanghuang" implementation plan. Participating units are required to strictly implement the "double innovation" implementation plan, actively explore project highlights, quantify and concrete patents, engineering methods, and "micro-innovation", and implement the implementation plan to specific locations.

\subsection{Compaction of safety responsibilities to ensure safe production}

Carefully learn the lessons of accidents, implement the responsibility of safety subjects, do a good job of safety and quality work, carry out daily inspections and regular inspections of hidden dangers of safety and quality, and take engineering safety and quality as prerequisites for double innovation to ensure foolproofness. Each participating construction unit seriously implements the safety work requirements of the provinces and cities, and strictly implements the leadership system and safety inspection system. Adhere to the red line of grasping quality and progress and never sacrificing safety at the expense of safety.

\section{References}

1. Wu, L.S., Guan, L., Huang, X.W., Liu, X.X.,(2019).Exploration and Research on Green Highway Construction of Yuewu Expressway in Anhui Province [J]. Energy Conservation and Environmental Protection of Transportation, 71 (03): 54-58.

2. Dong, R.C., (2019).Application and reflection of green highway concept in highway construction [J]. Green Environmental Protection Building Materials, 145 (03): $101+104$.

3. Mou, R.F., Che, C.,(2019).Attribute and Connotation Analysis of Green Highway $[\mathrm{J}]$. Journal of Transportation Engineering and Information Technology, 63 (01): 131-137.

4. Zhao, H., (2019).Application of Green Highway Concept in Zherong Expressway Design [J]. Energy Conservation and Environmental Protection in Transportation, 69 (01): 74-77.

5. Zhou, F.F., (2018)Construction of Green Highway Route Selection Index System Based on the Concept of Sustainable Development [J]. Highway, 63 (07): 106-111.

6. Ou, Y.B., Li, Z.K., (2014) Strategic Thinking of Green Highway Development [J]. Transportation Construction and Management,399 (22): 128-132 + 136.

7. Hao, P.W., Jiang, X.Q., Shi, Z.,(2011)oncept and Evaluation System of Green Highway [J]. Road Construction Machinery and Construction Mechanization, 196 (05): 30-35 + 11 .

8. Qin, X.C., Shen, Y., Shao, S.G., Huang, Y.J.,(2010)Discussion on the key technologies and 
applications of green highway construction under the concept of low carbon [J]. Journal of Highway and Transportation Research and Development (Application Technology Edition), 70 (10): 308-310+ 322.

9. Ma, Z.N., Gao, J.G.,(2006)Research on Green Highway Research System [J]. Journal of Highway and Transportation Research and Development, (09): 146-149. 